(C) <2014>. This manuscript version is made available under the CC-BY-NC-ND 4.0 license http://creativecommons.org/licenses/by-nc-nd/4.0/

\title{
Dissociative electron attachment and dipolar dissociation in ethylene
}

\author{
Ewelina Szymańska, Nigel J Mason \\ Department of Physical Sciences, The Open University, Milton Keynes, MK7 6AA, \\ United Kingdom
}

E Krishnakumar

Tata Institute of Fundamental Research, Homi Bhabha Road, Colaba, Mumbai 400005, India

Carolina Matias, Andreas Mauracher, Paul Scheier, Stephan Denifl

Institut für Ionenphysik und Angewandte Physik, Universität Innsbruck, Technikerstraße 25,

A-6020 Innsbruck, Austria

\begin{abstract}
We present a detailed experimental investigation of anion production in electron collisions with ethylene, $\mathrm{C}_{2} \mathrm{H}_{4}$. The investigated energy range is between 0 and $90 \mathrm{eV}$ where anions are formed by two processes, in the low energy regime by dissociative electron attachment (DEA) and at higher energy by dipolar dissociation (DD). These electron induced processes are studied in two different experimental apparatus using two different mass spectrometry techniques. One is a time of flight spectrometer operating with velocity slice imaging technique and the other is a two sector field mass spectrometer. The former allows efficient collection of ions compared to standard mass spectrometers, while the latter provides high mass resolution. Eight fragment anions formed via DEA in the electron energy range between 5 and $17 \mathrm{eV}$ have been detected; two fragments have not reported as DEA products in any previous studies. DD in $\mathrm{C}_{2} \mathrm{H}_{4}$ leads to the formation of the same anions as found in the case of DEA. Quantum chemical calculations have been carried out to determine the thermochemical thresholds of anion formation.
\end{abstract}




\section{Introduction}

Ethylene, $\mathrm{C}_{2} \mathrm{H}_{4}$, is one of the simplest hydrocarbons, also known as ethene. The chemical structure of ethylene is characterized by its two carbon atoms being bonded together in a double bond with all six atoms lying in the same plane, with $\mathrm{CCH}$ bond angles of $121.3^{\circ}$. Ethylene being a simple molecule is an ideal system for spectroscopic studies and to study electron collisions dynamics with hydrocarbons which are important in several technological applications (e.g., Ashfold et al. 2001). For example hydrocarbons are present in the edge plasma of fusion reactors (Frantz et al. 2005). Simple hydrocarbon molecules like ethylene are released by chemical erosion of the plasma vessel due to plasma-wall interactions. Radiative and collisional processes in the plasma edge region involving hydrocarbons play a major role in the dynamics and subsequent stability of the core plasma. It should be noted that, although attempts have been made to replace carbon based composites by other materials such as tungsten or beryllium; diverters still consist preferentially of carbon due to the high heat load (Frantz et al 2005). Hence data on electron - hydrocarbon collisions including data for ethylene are important in simulations of the transport of impurities and their chemistry in the scrape-off layer plasma.

To date ethylene has rarely been observed in Space, but Betz (1981) identified two absorption lines in the circumstellar gas surrounding the carbon rich AGB star IRC+10216. Later in the same interstellar source, new absorption lines of ethylene have also been detected by Goldhaber et al. (1987) and Hinkle et al. (2008). Ethylene also plays an important role in the photochemistry of planetary atmospheres (Strobel et al. 1992, Roe et al. 2004\}. Ethylene is present in the Earth's troposphere as a pollutant, produced by the road traffic and biomass burning. It is also present in the atmosphere of giant planets (Jupiter, Saturn; Bezard et al. 2001) and of large moons such as Titan.

Electron-ethylene collision data have been collected by many groups and a summary compiled in the HYDKIN database (Huber et al. 2011 and Reiter and Janev 2010) which include (dissociative) electron ionization cross sections, recombination cross sections as well as dissociative electron excitation cross sections for ethylene. However, to date, there only a few studies of dissociative electron attachment (DEA) and dipolar dissociation (DD) processes in ethylene. The absolute total attachment cross section in the energy range up to 10 eV was measured by Rutkowsky et al. (1980). They used a total ionization tube, i.e. no mass spectrometer was attached, to obtain partial DEA cross sections of fragment anions. The total anion yield showed one single peak at about $10 \mathrm{eV}$ with a cross section value of $4.5 \times 10^{-20} \mathrm{~cm}^{2}$ 
(Rutkowsky et al. 1980). Melton and Rudolph (1959) reported the first experimental studies of electron induced anion formation from ethylene and determined possible fragmentation channels. Their experimental approach was to record the negative ion mass spectrum at incident electron energy of $90 \mathrm{eV}$, i.e. the formation of anions by DD was investigated. In their paper, they derived the percentage of $\mathrm{C}^{-}, \mathrm{CH}^{-}, \mathrm{CH}_{2}{ }^{-}, \mathrm{C}_{2}{ }^{-}, \mathrm{C}_{2} \mathrm{H}^{-}, \mathrm{C}_{2} \mathrm{H}_{2}{ }^{-}$and $\mathrm{C}_{2} \mathrm{H}_{3}{ }^{-}$anions from ethylene as 15.2, 10.3, 4.0, 39.3, 30.1, 0.9 and 0.2, respectively. Later, a detailed mass spectrometric study of anion production in several small hydrocarbons including ethylene was performed by von Trepka and Neuert (1963) and they determined the ion yield of fragment anions as function of the electron energy. In addition they estimated the electron affinity of the fragments from the experimentally observed appearance energies of anions (von Trepka and Neuert 1963). Thynne and MacNeil (1971) reported the anion mass spectra of DD recorded at an incident electron energy of $70 \mathrm{eV}$ and measure the ion yield as a function of the electron energy for $\mathrm{CH}^{-}, \mathrm{CH}_{2}{ }^{-}$and $\mathrm{C}_{2} \mathrm{H}^{-}$anions formed by DEA processes. Particularly rare are data on $\mathrm{H}^{-}$production due to its low mass and corresponding detection problems with conventional mass spectrometers. Most recently low energy $\mathrm{H}^{-}$production from ethylene was presented by Cadez et al. (2012) using a dedicated apparatus to measure the $\mathrm{H}^{-}$(Cadez et al. 2012). Cadez et al. (2012) showed the $\mathrm{H}^{-}$ion yield from $\mathrm{C}_{2} \mathrm{H}_{4}$, consists of three overlapped DEA peaks at 7.6, 9.1 and $10.7 \mathrm{eV}$ and reported the threshold energy of DD production at $13.5 \mathrm{eV}$. The required excitation of the neutral target molecule which leads to DD can be produced not only by electrons but also by photons. This process of photon induced DD was shown in the photo-ionization study of Mackie et al. (2003) which revealed the formation of the $\mathrm{H}^{-}$anion from ethylene with a threshold close to its thermochemical value of $12.55 \mathrm{eV}$. In addition, Mackie et al. (2003) observed a pronounced structure in the $\mathrm{H}^{-}$photo-ion yield, which was similar to structure in the photoabsorption spectrum of ethylene. The authors concluded that not only the pre-dissociation of super excited Rydberg states into neutrals competes with autoionization but predissociation by DD as well. These authors did not report the observation of any other anions in the photon energy range from 15 to $30 \mathrm{eV}$.

Table 1 shows an overview of previous results reporting detection of anion fragments produced by DEA and DD as well as the relative abundances of the fragment anions formed upon DD. The table shows significant discrepancies in the relative abundances of DD, as well as discrepancies in the type of fragment anions for DEA. In the present study we present a detailed investigation of the anion yields formed by DEA and DD in ethylene over the energy range between 0 and $90 \mathrm{eV}$. These electron induced anion processes were investigated using a time of flight spectrometer operating with the velocity slice imaging technique (TOF-VSI) 
and a two sector field mass spectrometer (VG-ZAB) with high mass resolution and high sensitivity shortly described in the next section.

\section{Experimental}

Two different experimental setups were used in the present investigations, (i) a time of flight spectrometer operating with velocity slice imaging technique (TOF-VSI) at the Open University in Milton Keynes in United Kingdom and (ii) a two sector field mass spectrometer (VG-ZAB) situated at the Institute of Ion Physics and Applied Physics at the University of Innsbruck in Austria.

An improved version of a time of flight (TOF) spectrometer operating with velocity slice imaging (VSI) technique described in an earlier publication (Nandi et al. 2005) was used. In brief, it consists of perpendicularly crossed molecule and electron beams, generated from an effusive gas capillary and an electron gun respectively, a TOF spectrometer in the VSI configuration and a position sensitive detector (PSD). A 200 ns wide pulsed and magnetically collimated electron beam is generated from an electron gun with an energy resolution of approximately $0.5 \mathrm{eV}$. A pair of coils arranged in Helmholtz geometry generates a uniform magnetic field $(50 \mathrm{G})$ to collimate the electron beam into an interaction region from which product anions are extracted and launched into the TOF-VSI spectrometer using a pulsed electric field applied $200 \mathrm{~ns}$ after the electron pulse. A two-dimensional PSD made of three micro-channel plates (75 $\mathrm{mm}$ diameter) and a phosphor screen with pulsed bias is used to image the product anions. The biases on the detector and the phosphor screen can be pulsed simultaneously with a $2 \mathrm{kV}$ pulse with variable delay in order to detect ions of given mass to charge ratio; i.e. to measure the anion flight time. We can operate the instrument as a simple TOF spectrometer operating in an ion counting mode with the detector continuously biased. We can also selectively detect a narrow central slice of the Newton sphere of a specific ion species by controlling the width of the pulse. However in the case of measurements in ethylene, the velocity images were not recorded, due to very low cross sections for DEA.

The high resolution double focusing two sector field mass spectrometer (VG-ZAB) has a reversed Nier-Johnson type geometry (i.e. magnetic sector field followed by the electric sector field) and was described in detail by Huber et al. (2006). Briefly, an effusive beam of ethylene was introduced into a Nier-type ion source where it was crossed with an electron beam. The electrons were guided by a homogeneous magnetic field of about $20 \mathrm{mT}$. This field 
is sufficiently high to prevent extraction of electrons from the ion source. The energy resolution of the electron beam was approximately $1 \mathrm{eV}$ at an electron current of $10 \mu \mathrm{A}$. The anions formed in the ion source were extracted by a weak electric field and accelerated through a potential drop of $6 \mathrm{kV}$ into the mass spectrometer. The ions passed through the first field-free region, were momentum analysed by a magnetic sector field, entered a second fieldfree region, passing through an $81^{\circ}$ electric sector field, and finally were detected by a channel electron multiplier operating in the pulse counting regime. In order to detect all the fragment anions formed upon DEA to ethylene anion mass spectra were recorded at several electron energies. Furthermore, anion efficiency curves were measured for all anions discovered in the mass spectra by measuring the ion yield as a function of the electron energy from about 0 to $27 \mathrm{eV}$. The measurements were carried out having a mass resolution of $\mathrm{m} / \Delta \mathrm{m}$ of about 1100. This mass resolution was not sufficient to separate the isobaric anions $\mathrm{C}_{2} \mathrm{H}_{2}{ }^{-}$ and $\mathrm{CN}^{-}$(mass difference $0.0125 \mathrm{u}$ ) (Mauracher et al. 2007), however, the latter anion was also present as residual ion yield on the nominal mass $26 \mathrm{u}$. Hence, the ion yield of $\mathrm{C}_{2} \mathrm{H}_{2}{ }^{-}$ (exact mass $26.01567 \mathrm{u}$ ) was determined at $26.03 \mathrm{u}$ in order to avoid any contribution from $\mathrm{CN}^{-}$in the ion yield.

In TOF-VSI and VG-ZAB experiments, ethylene was drawn from a gas cylinder by Air Products Ltd and Messer Austria GmbH, respectively and was connected to the vacuum chamber via a gas line with a precision leak valve. The working pressure was $5 \times 10^{-6} \mathrm{mbar}$ in both the TOF-VSI and VG-ZAB chambers. In the TOF-VSI experiment the anion mass scale was calibrated using two reference gases: $\mathrm{O}_{2}$ and $\mathrm{CF}_{4}$ with the absolute electron energy scale calibrated using the well-known resonance energy at $6.5 \mathrm{eV}$ in the DEA reaction $\mathrm{e}+\mathrm{O}_{2} \rightarrow$ $\mathrm{O}^{*^{-}} \rightarrow \mathrm{O}^{-}+\mathrm{O}$ (Nandi et al. 2005). In the case of VG-ZAB experiment, the anion mass scale and the absolute electron energy scale were calibrated using well known attachment peaks in $\mathrm{SF}_{6}$ (Fenzlaff et al. 1988).

\section{Computational}

The energies of all dissociative electron attachment and dipolar dissociation reactions discussed in the present study have been determined employing thermochemical calculations. The various extrapolation schemes used are G4(MP2) (Curtiss et al. 2007), G4 (Curtiss et al. 2007a), CBS (Montgomery Jr. et al. 2000) and W1 (Martin et al. 1999) which are all considered to be highly accurate. In particular G4(MP2) yields an average absolute deviation 
from experiment for the 454 energies in the G3/05 test set of $1.04 \mathrm{kcal} / \mathrm{mol}$ (Curtiss et al. 2007), whereas the other methods can be regarded as at least equally accurate. We find that all schemes yield very similar results, except for the well-known deficiency concerning the electron affinity of atomic hydrogen (see Table 2 for a list of electron affinities of all species involved). We compare our theoretical values with experimental data as obtained from the NIST database (NIST 2013). In this respect we want to stress that the electron affinities reported in the NIST database are results from laser photoelectron spectroscopy (LPES) measurements. Hence these numbers correspond to vertical detachment energies (VDEs) rather than adiabatic electron affinities (AEAs). However, in case of small changes in the geometry from the neutral to the anionic systems, VDEs correspond approximately to AEAs. Following reactions have been considered,

$\mathrm{C}_{2} \mathrm{H}_{4}+\mathrm{e}^{-} \rightarrow \mathrm{C}_{2} \mathrm{H}_{3}^{-}+\mathrm{H}$

$\mathrm{C}_{2} \mathrm{H}_{4}+\mathrm{e}^{-} \rightarrow \mathrm{C}_{2} \mathrm{H}_{2}^{-}+2 \mathrm{H}$ (both $\mathrm{H}$ from same side)

$\mathrm{C}_{2} \mathrm{H}_{4}+\mathrm{e}^{-} \rightarrow \mathrm{HCCH}^{-}+2 \mathrm{H}$

$\mathrm{C}_{2} \mathrm{H}_{4}+\mathrm{e}^{-} \rightarrow \mathrm{C}_{2} \mathrm{H}^{-}+3 \mathrm{H}$

$\mathrm{C}_{2} \mathrm{H}_{4}+\mathrm{e}^{-} \rightarrow \mathrm{C}_{2}^{-}+4 \mathrm{H}$

$\mathrm{C}_{2} \mathrm{H}_{4}+\mathrm{e}^{-} \rightarrow \mathrm{CH}_{2}^{-}+\mathrm{C}+2 \mathrm{H}$

$\mathrm{C}_{2} \mathrm{H}_{4}+\mathrm{e}^{-} \rightarrow \mathrm{CH}^{-}+\mathrm{C}+3 \mathrm{H}$

$\mathrm{C}_{2} \mathrm{H}_{4}+\mathrm{e}^{-} \rightarrow \mathrm{C}^{-}+\mathrm{C}+4 \mathrm{H}$

$\mathrm{C}_{2} \mathrm{H}_{4}+\mathrm{e}^{-} \rightarrow \mathrm{H}^{-}+2 \mathrm{C}+3 \mathrm{H}$

In Table 3 we summarize the reaction energies for reactions (1) to (9). Note that the neutral fragments formed upon DEA are all atomic species. Hence these energies correspond to the highest reaction energies obtainable. Of course it is possible to form molecular neutral species in such interactions. Therefore we list in Table 4 the atomization energies (ATEs) of all considered fragments, see reaction $(10)-(17)$,

$$
\begin{aligned}
& \mathrm{H}_{2} \rightarrow 2 \mathrm{H} \\
& \mathrm{CH} \rightarrow \mathrm{C}+\mathrm{H} \\
& \mathrm{CH}_{2} \rightarrow \mathrm{C}+2 \mathrm{H} \\
& \mathrm{CH}_{3} \rightarrow \mathrm{C}+3 \mathrm{H} \\
& \mathrm{CH}_{4} \rightarrow \mathrm{C}+4 \mathrm{H} \\
& \mathrm{C}_{2} \rightarrow 2 \mathrm{C} \\
& \mathrm{C}_{2} \mathrm{H} \rightarrow 2 \mathrm{C}+\mathrm{H} \\
& \mathrm{C}_{2} \mathrm{H}_{3} \rightarrow 2 \mathrm{C}+3 \mathrm{H}
\end{aligned}
$$


In addition, we also calculated ionization energies (IEs) for ethylene molecule and possible fragments in order to derive the thresholds for dipolar dissociation (Table 5).

\section{Results and Discussion}

Anionic mass spectra of ethylene were recorded at different incident electron energies using both the VG-ZAB and TOF-VSI apparatus. Figure 1 shows anionic mass spectra recorded at an incident electron energy of $70 \mathrm{eV}$ after subtraction of backgrounds in the both experimental apparatus described above. The anionic mass spectrum collected at $70.0 \mathrm{eV}$ using VG-ZAB reveals the formation of $\mathrm{H}^{-}(1 \mathrm{u}), \mathrm{C}^{-}(12 \mathrm{u}), \mathrm{CH}^{-}(13 \mathrm{u}), \mathrm{CH}_{2}^{-}(14 \mathrm{u}), \mathrm{C}_{2}^{-}(24$ $\mathrm{u}), \mathrm{C}_{2} \mathrm{H}^{-}(25 \mathrm{u}), \mathrm{C}_{2} \mathrm{H}_{2}^{-}(26 \mathrm{u})$ and $\mathrm{C}_{2} \mathrm{H}_{3}^{-}(27 \mathrm{u})$; while the anionic mass spectrum recorded using TOF-VSI shows formation of $\mathrm{H}^{-}$and two broad peaks composed of other anions at higher masses. Due to the low mass resolution $(\sim 1)$ of the time of flight analyser in the TOFVSI setup we were not able to directly distinguish individual contributions in the mass spectrum at higher masses and thus we define for the following discussion the group comprised of $\mathrm{C}^{-}, \mathrm{CH}^{-}$and $\mathrm{CH}_{2}^{-}$as $\mathrm{C}_{1}$ anion group and the group comprised of $\mathrm{C}_{2}^{-}, \mathrm{C}_{2} \mathrm{H}^{-}$, $\mathrm{C}_{2} \mathrm{H}_{2}{ }^{-}$and $\mathrm{C}_{2} \mathrm{H}_{3}{ }^{-}$as $\mathrm{C}_{2}$ anion group. The VG-ZAB mass spectrum was normalized to the most intense peak of $\mathrm{C}_{2} \mathrm{H}^{-}$, while the TOF-VSI mass spectrum was normalized to the $\mathrm{H}^{-}$peak. Thus the data from the two different experiments show dramatic differences in the relative abundance of $\mathrm{H}^{-}$to the heavier fragment anions. This difference can be explained by different experimental settings and conditions in the two apparatus. The TOF-VSI apparatus was set up for collection of small anions, especially for complete $\mathrm{H}^{-}$collection as achieved in a recent study on absolute cross sections of $\mathrm{H}^{-} / \mathrm{H}_{2}$ (Krishnakumar et al. 2011) while in the VG-ZAB it can be expected that a large fraction of the product $\mathrm{H}^{-}$anions are discriminated in the ion source as well as in the mass spectrometer. The latter can be also expected for all previous DD studies, where the $\mathrm{H}^{-}$yield was lower than the most abundant fragment $\mathrm{C}_{2}^{-}$ranging between a factor 1.66 in von Trepka and Neuert (1963) and 12.5 in Thynne and MacNeil (1871). Melton and Rudolph (1959) did not measure the $\mathrm{H}^{-}$intensity due to instrumental difficulties.

We also recorded electron energy dependent anion efficiency curves (a measure of the anion yield as a function of electron energy) for each of the peaks observed in the anionic mass spectra. In the TOF-VSI setup the ion yield curves were obtained by selecting the time window corresponding to each mass peak. Figure 2 presents the anion yields for formation of 
$\mathrm{H}^{-}$and the two groups of anions $\mathrm{C}_{1}$ and $\mathrm{C}_{2}$ from ethylene in the incident electron energy range of $0-90 \mathrm{eV}$ recorded with the TOF-VSI apparatus. While the peaks at lower electron energy around $10 \mathrm{eV}$ can be ascribed to DEA, the considerable yield at higher energies arises from DD. The shape of the DD is characterized by a steep onset between about 13.5 and $21.5 \mathrm{eV}$ which is discussed below in more detail. With increasing electron energy the yield starts to plateue between 30 and $40 \mathrm{eV}$ and increases only slightly up to the maximum energy used in the experiment of $90 \mathrm{eV}$. The shape is reminiscent of typical electronic excitation functions obtained in emission spectroscopy of fragments excited by electron impact of ethylene (Aarts et al. 1971). This clearly indicates that super excited states are formed as intermediates which decay by DD, fluorescence or auto ionization (Danko et al. 2013). Moreover, the DD ion yield between 40 and $90 \mathrm{eV}$ may indicate several peaks and shoulders. However, we ascribe these structures rather to limited statistics in the data collection than to real features in the DD cross section.

Figure 3 shows the anion yield for the formation of $\mathrm{H}^{-}$from ethylene in the incident electron energy range of $5-20 \mathrm{eV}$ in more detail. The data shown was recorded using both the TOF-VSI and VG-ZAB apparatus, for comparison the Figure 3 also includes the recent $\mathrm{H}^{-}$ measurement by Cadez et al. (2012). The top-right inset of Figure 3 shows the TOF-VSI H anion yield at low electron energies (black circles) while the solid lines were determined by Gaussian fitting of the resonance features. The $\mathrm{H}^{-}$anion yield exhibits three overlapping contributions from DEA centered at 7.6, 8.8 and $10.7 \mathrm{eV}$. Table 6 summarizes the peak positions for different anionic fragments recorded in the present experiments compared with the available previously published data. The peak positions in the present TOF-VSI experiment are in good agreement with the VG-ZAB data and earlier data by Cadez et al. (2012). In contrast von Trepka and Neuert (1963) were not able to resolve the first two weaker resonances while the main resonance was located at $11 \mathrm{eV}$. They reported the appearance energy (AE) of $7.6 \pm 0.3 \mathrm{eV}$ for the first resonance and $9.7 \pm 0.4 \mathrm{eV}$ for the main resonance, i.e. peak positions as well as resonance maxima are slightly shifted compared to more recent data. Von Trepka and Neuert (1963) also made a tentative assignment of the neutral fragmentation products formed in the $\mathrm{H}^{-}$production. They quoted the onset value of $7.6 \mathrm{eV}$ (first resonance) to the $\mathrm{H}^{-}+\mathrm{C}_{2} \mathrm{H}_{3}$ dissociation channel, while second onset value of $9.7 \mathrm{eV}$ (main resonance at $11 \mathrm{eV}$ ) to a three body fragmentation via $\mathrm{H}^{-}+\mathrm{CH}_{2}+\mathrm{CH}$ dissociation channel. The present calculations yield a thermochemical threshold of $4.45 \mathrm{eV}$ for the former channel and $11.52 \mathrm{eV}$ for the latter. Hence we can exclude that $\mathrm{C}_{2} \mathrm{H}_{3}$ will break up in $\mathrm{CH}_{2}+\mathrm{CH}$ in the DEA process. However, it should be noted that another three body 
fragmentation channel $\left(\mathrm{H}^{-}+\mathrm{C}_{2} \mathrm{H}+\mathrm{H}_{2}\right)$ has a particular low thermochemical threshold of 7.17 $\mathrm{eV}$ which is energetically possible for the second and third resonances.

The sensitivity of the experimental setup in Thynne and MacNeil (1971) was not sufficient to measure $\mathrm{H}^{-}$anion yields due the general low DEA cross section for ethylene. Although the TOF-VSI indicates that $\mathrm{H}^{-}$is by far the dominant fragmentation channel upon DEA, the total DEA cross sections presented in Rutkowsky et al. (1980) reported only a single peak with a maximum at about $10.6 \mathrm{eV}$. The absence any yield at lower energies in the total cross section is rather surprising since the total ionization tube employed earlier should ensure a high collection efficiency of ions as in the present TOF-VSI experiment.

Increasing the electron energy revealed a feature in $\mathrm{H}^{-}$ion yield formed via DD. A threshold for DD was determined to be around $13.5 \mathrm{eV}$. Figure 3 indicates slight differences in the DD ion yields for the different setups used here and the previous data by Cadez et al. (2012). While the TOF-VSI and Cadez et al. (2012) data have a very similar onset, the DD yield increases steeper in the latter. The VG-ZAB data shows a higher AE with a more slowly increasing ion yield. Further investigations have been carried out to investigate possible reasons for this discrepancy in the threshold behaviour and it was found that the onset was (non-linearly) dependent on the acceleration voltage used to extract the anions out of the ion source. When the acceleration voltage was varied between 5.7 and $7.3 \mathrm{kV}$, the threshold shifted up to $2.5 \mathrm{eV}$. This dependence may indicate different focusing conditions of the extraction field in the VG-ZAB apparatus for different acceleration voltages. Hence, in order to derive the AE value, we only considered the TOF-VSI data for further analysis where no differences were observed in the onset when extraction conditions were changed. The energy thresholds of DD processes were determined using a function described by Denifl et al. (2006).

$$
\begin{array}{ll}
f(E)=b & \text { for } E<A E \\
f(E)=b+a(E-A E)^{n} & \text { for } E>A E
\end{array}
$$

This pair of functions coupled through the parameter $b$ which describes the background signal is simultaneously fitted toa complete set of data points. The fit involves four parameters, $b$, $a$, $\mathrm{AE}$ and $\mathrm{n}$. Figure 4a presents the anion yield of $\mathrm{H}^{-}$close to the onset of DD together with the fit based on Equation 18a and 18b. A threshold of about $13.5 \mathrm{eV}$ is observed which is very good agreement with Cadez et al. (2012) who also reported the threshold energy for $\mathrm{H}^{-}$ formation by the DD process at $13.5 \mathrm{eV}$. 
We also calculated the thermochemical energy thresholds for the DD process which leads to formation of $\mathrm{H}^{-}$and different cationic and neutral counterparts (Table 7). The appearance energy for the production of positive ion $\mathrm{B}^{+}, \mathrm{AE}_{\mathrm{B}}$, and the electron affinities $\mathrm{AE}_{\mathrm{A}}$ were taken from the present thermochemical data except the EA for $\mathrm{H}$ which was taken from Rienstra-Kiracofe et al. (2002). The calculated threshold value for the energetically lowest possible channel (involves formation of $\mathrm{H}^{-}+\mathrm{C}_{2} \mathrm{H}_{3}{ }^{+}$) is $12.65 \mathrm{eV}$ which is about one $\mathrm{eV}$ below the DD-threshold observed experimentally. Other reaction channels which involve the dissociation of the $\mathrm{C}_{2} \mathrm{H}_{3}{ }^{+}$into a fragment ion and a neutral fragment have a considerably higher threshold of at least $18.5 \mathrm{eV}$ which corresponds to the threshold for $\mathrm{H}^{-}+\mathrm{C}_{2} \mathrm{H}_{2}^{+}+\mathrm{H}$. Hence we ascribe the DD ion signal observed in Figure 4 to $\mathrm{H}^{-}+\mathrm{C}_{2} \mathrm{H}_{3}{ }^{+}$. At higher electron energies the thresholds for other dissociation channels may be hidden in the ion yield shown in Figure $4 \mathrm{a}$ and cannot be resolved due to the finite energy resolution of the electron beam and finite statistics.

Figure 5a and 6a compare of $\mathrm{C}_{1}$ and $\mathrm{C}_{2}$ group anions measured with TOF-VSI and the sum of the mass resolved ion yields (i.e. $\mathrm{C}^{-}, \mathrm{CH}^{-}$and $\mathrm{CH}_{2}^{-}$comprising $\mathrm{C}_{1}$ group and $\mathrm{C}_{2}^{-}$, $\mathrm{C}_{2} \mathrm{H}^{-}, \mathrm{C}_{2} \mathrm{H}_{2}{ }^{-}$and $\mathrm{C}_{2} \mathrm{H}_{3}{ }^{-}$comprising $\mathrm{C}_{2}$ group) determined with the VG-ZAB apparatus. Taking into account the lower signal/noise ratio in the TOF-VSI data very good agreement is observed in DEA yields while for DD formation the agreement is less satisfactorily due to the reasons mentioned above. The corresponding mass resolved ion yields are shown in Figure $5 b-d$ and $6 b-e$, respectively. The DEA ion yield of $\mathrm{C}^{-}$is the weakest ofall fragment anions and has not been reported before. It is formed most abundantly in a resonance close to $15 \mathrm{eV}$ and very weakly at about $10 \mathrm{eV}$. The thermochemical thresholds for different dissociation reactions can be found in Table 6 . The first (very weak) resonance may be ascribed to $\mathrm{C}^{-}+$ $\mathrm{CH}_{4}$ with a thermochemical threshold of $4.91 \mathrm{eV}$, while $\mathrm{C}^{-}+\mathrm{CH}_{2}+\mathrm{H}_{2}$ formation may occur in the second resonance. In addition, a third very weak resonance appears between 15 and 20 $\mathrm{eV}$, which may be ascribed to $\mathrm{C}^{-}+\mathrm{CH}_{2}+\mathrm{H}+\mathrm{H}(14.04 \mathrm{eV})$.

As mentioned the resonance in the $\mathrm{C}^{-}$ion yield at about $10 \mathrm{eV}$ is very weak; however, this resonance is the strongest one in most other fragment anions. The appearance of the resonance peak for all other fragment anions indicates a common transient negative ion state. Another TNI state is present at about $7.5 \mathrm{eV}$, which can be observed however only for $\mathrm{C}_{2} \mathrm{H}_{3}{ }^{-}$, $\mathrm{C}_{2} \mathrm{H}_{3}{ }^{-}, \mathrm{C}_{2} \mathrm{H}^{-}$and $\mathrm{H}^{-}$. In addition, comparison of the relative intensities of resonances in Figures 3, 5 and 6 shows that resonances at higher electron energies are more abundant if more bonds in DEA process are broken. This result can be explained in terms of a higher 
excess energy deposited in the transient negative ion, when it is formed at higher electron energies.

All the heavier fragment anions also show a clear onset for DD, which is visible in Figures 5 and 6. Since the DD threshold for $\mathrm{CH}_{2}{ }^{-}$is several $\mathrm{eV}$ lower than for $\mathrm{CH}^{-}$and $\mathrm{C}^{-}$the lowest threshold visible in the TOF-VSI corresponds to that of $\mathrm{CH}_{2}{ }^{-}$. This is also the case for the $\mathrm{C}_{2}$ group where $\mathrm{C}_{2} \mathrm{H}_{3}{ }^{-}$has a significantly lower threshold than the other fragment anion of this group. Thus the TOF-VSI signal close to threshold of the $\mathrm{C}_{1}$ and $\mathrm{C}_{2}$ group shown in Figure $4 \mathrm{~b}$ and $4 \mathrm{c}$ corresponds to DD signal from $\mathrm{CH}_{2}{ }^{-}$and $\mathrm{C}_{2} \mathrm{H}_{3}{ }^{-}$, respectively. As for the $\mathrm{H}$ channel, the comparison with calculated DD thresholds is included in Table 5. While for DD leading to $\mathrm{CH}_{2}^{-}+\mathrm{CH}_{2}^{+}$fair agreement can be observed, the deviation between thermochemistry and experiment is large for $\mathrm{C}_{2} \mathrm{H}_{3}{ }^{-}+\mathrm{H}^{+}$and amounts about $3.8 \mathrm{eV}$ (see Table $5)$.

The DEA ion yields of $\mathrm{C}_{1}$ and $\mathrm{C}_{2}$ group anions are in most cases in good agreement with previous data by von Trepka and Neuert (1963) and Thynne and MacNeil (1971) (see Table 3). Exceptions can be found for $\mathrm{C}_{2} \mathrm{H}^{-}$where the peak position of the first resonance deviates by one $\mathrm{eV}$ and in addition, we were not able to observe clear signatures of the first weak resonances in the $\mathrm{CH}^{-}$and $\mathrm{CH}_{2}^{-}$ion yields within the detection limit of the apparatus. Thynne and MacNeil (1971) derived appearance potentials for $\mathrm{CH}^{-}$at 7.0 and $8.4 \mathrm{eV}$ (von Trepka and Neuert (1963) reported 7.3 and $8.7 \mathrm{eV}$ ), which were associated with the formation of this anion via $\mathrm{CH}^{-}+\mathrm{CH}_{3}$ and $\mathrm{CH}^{-}+\mathrm{CH}_{2}+\mathrm{H}$ dissociation channels, respectively. The present calculations give onset values of $5.86 \mathrm{eV}$ and $10.61 \mathrm{eV}$, respectively, which support the previous assignment of $\mathrm{CH}^{-}+\mathrm{CH}_{3}$ to the first resonance while the threshold for $\mathrm{CH}^{-}+$ $\mathrm{CH}_{2}+\mathrm{H}$ seems too high for assignment to the second resonance at $10 \mathrm{eV}$. Instead it may be assigned to the third resonance at $15 \mathrm{eV}$; however, the $\mathrm{CH}^{-}+\mathrm{CH}+\mathrm{H}_{2}$ has a similar threshold value of 10.46, hence the actial assignment must remain ambiguous.

Previously Thynne and MacNeil (1971) reported two onsets at 7.8 and $9.1 \mathrm{eV}$ for $\mathrm{CH}_{2}{ }^{-}$ formation with associated peak maxima at $8.8 \mathrm{eV}$ and $10.3 \mathrm{eV}$. They assigned the peaks to symmetrical splitting of ethylene, $\mathrm{CH}_{2}{ }^{-}+\mathrm{CH}_{2}$ for the first resonance and $\mathrm{CH}_{2}{ }^{-}+\mathrm{CH}+\mathrm{H}$, for the second resonance. However, it should be noted that von Trepka and Neuert (1963) reported only one appearance energy at $8.8 \mathrm{eV}$ and in the present data we observe only one resonance at about $10 \mathrm{eV}$. Based on our calculations we assign the resonance to the symmetrical splitting of ethylene in the DEA process $(6.84 \mathrm{eV})$ while the second energetically lowest channel $\left(\mathrm{CH}_{2}^{-}+\mathrm{CH}+\mathrm{H}\right)$ has a threshold of $10.17 \mathrm{eV}$ and thus lies above the resonance maximum. 
The yield of $\mathrm{C}_{2}$ group anions Thynne and MacNeil (1971) show three resonance peaks at about 8.5, 9.5 and $10.7 \mathrm{eV}$ in the most abundant anion yield of $\mathrm{C}_{2} \mathrm{H}^{-}$. The corresponding onsets reported were 6.9, 8.8 and $9.8 \mathrm{eV}$ respectively. The second onset was not reported in the studies by von Trepka and Neuert (1963) and the present data shows no obvious indication of a resonance close to $9.5 \mathrm{eV}$. Thynne and MacNeil (1971) assigned the first $8.5 \mathrm{eV}$ resonance peak to formation of $\mathrm{C}_{2} \mathrm{H}^{-}+\mathrm{H}_{2}+\mathrm{H}$ dissociation channel, while the second resonance peak at $9.5 \mathrm{eV}$ was associated with the $\mathrm{C}_{2} \mathrm{H}+3 \mathrm{H}$ pathway; and the third resonance at $9.8 \mathrm{eV}$ was ascribed to both dissociation channels with 5.4 and 0.8 excess energy, respectively (Thynne and MacNeil 1971). In the present work, the second resonance was not clearly observed within our detection limits (see Figure 6). The calculated thermochemical thresholds are in agreement with previous assignments (see Table 6).

Von Trepka and Neuert (1963) reported the appearance energy for $\mathrm{C}_{2}^{-}$formation at $10.4 \mathrm{eV}$, which is already quite close to the peak maximum of $\mathrm{C}_{2}^{-}$observed in the present studies $(\sim 10.5 \mathrm{eV})$. Comparison with calculations shows, that the resonance is accompanied by formation of a $\mathrm{H}_{2}$ molecule in the DEA reaction. A broad weak resonance at about $17 \mathrm{eV}$ may be formed via release of four single hydrogen atoms (thermochemical threshold 13.63 $\mathrm{eV})$.

For $\mathrm{C}_{2} \mathrm{H}_{3}{ }^{-}$no peak positions or onsets were reported previously and only the relative abundance was reported by Von Trepka and Neuert (1963). The thermochemical onset is 4.06 $\mathrm{eV}$, i.e. a weaker yield in the second resonance at about $10 \mathrm{eV}$ compared to the first one at about $7.5 \mathrm{eV}$ can be explained by the considerable higher excess energy released in the second resonance which leads to subsequent dissociation. The $\mathrm{C}_{2} \mathrm{H}_{2}^{-}$anion was not reported at all in previous studies. In the present measurements we observe the anion at the resonance energy of about $7.4 \mathrm{eV}$ while the second resonance can be ascribed to the vinylene anion, ${ }^{13} \mathrm{CCH}^{-}$isotope (see Figure 6c). Calculations indicate that the vinylene anion with one hydrogen atom removed from each carbon atoms has a negative electron affinity, i.e. it is not expected to be detected in the present experiment. Instead the vinylene anion (both hydrogen from one carbon atom were removed in the dissociation process) has a slightly positive electron affinity of $0.5 \mathrm{eV}$ and hence may be the favoured structure formed in the DEA to ethylene. Moreover, we ascribe the formation to $\mathrm{C}_{2} \mathrm{H}_{2}{ }^{-}+\mathrm{H}_{2}$ (threshold $3.16 \mathrm{eV}$ ) which may be supported by the proximity of the two hydrogen atoms released. 


\section{Conclusion}

We studied anion formation in the electron energy range between 0 and $90 \mathrm{eV}$. For electron energies between 5 and $17 \mathrm{eV}$ DEA resonances can be observed while at higher energies ( $>13.5 \mathrm{eV})$ DD occurs. In DEA to ethylene $\mathrm{H}^{-}, \mathrm{C}^{-}, \mathrm{CH}^{-}, \mathrm{CH}_{2}^{-}, \mathrm{C}_{2}^{-}, \mathrm{C}_{2} \mathrm{H}^{-}, \mathrm{C}_{2} \mathrm{H}_{2}^{-}$and $\mathrm{C}_{2} \mathrm{H}_{3}{ }^{-}$anions can be observed. The present calculations of thermochemical thresholds indicate that for several resonances formation of stable neutral molecules from released fragments occurs which lowers the threshold of the DEA reaction. $\mathrm{C}^{-}$and $\mathrm{C}_{2} \mathrm{H}_{2}^{-}$were not reported in previous DEA experiments with ethylene while the other fragment anions show in most cases reasonable agreement with previous data concerning ion yield shapes. The same anions formed by DEA are also formed at higher electron energies by dipolar dissociation. Compared to previous experiments and to the present results obtained with the VG-ZAB apparatus, the $\mathrm{H}^{-}$anion yield has the highest abundance relative to other fragment anions in the TOF-VSI instrument. The TOF-VSI instrument allows discrimination-free collection of $\mathrm{H}^{-}$ions, i.e. we can conclude that the relative abundance of $\mathrm{H}^{-}$is strongly underestimated when using standard mass spectrometers as in previous experiments and observed in the VG-ZAB apparatus.

\section{Acknowledgements}

This work was supported in part by the Austrian Science Fund, Wien (FWF, project P22665). ES and NJM acknowledge the LASSIE project (LASSIE is supported by the European Commission's 7th Framework Programme under Grant Agreement n 238258). Authors would like to thank Iztok Cadez and Stefan Huber for fruitful discussions during the measurements and calculations, respectively. A.M. acknowledges the High Performance Computing (HPC) platform of the University of Innsbruck 


\section{Bibliography}

Aarts J F M, Beenakker C I M, De Heer F J Physica (1971) 53 32-44

Ashfold M, May P, Petherbridge J, Rosser K, Smith J, Mankelevich Y and Suetin N Phys Chem Chem Phys (2001) 33471

Betz A Astrophys J (1981) 244 L103

Bezard B, Moses J, Lacy J, Greathouse T, Richter M and Grith C Bull Amer Astron Soc (2001) 331079

Cadez I, Markelj S and Rupnik Z Eur Phys J D (2012) 6673

Curtiss L A, Redfern P C, and Raghavachari K J. Chem. Phys. (2007) 127124105

Curtiss L A, Redfern P C, and Raghavachari K J. Chem. Phys.(2007) 126084108

Danko M, Orszagh J, Ďurian M, Kočišek J, Daxner M, Zöttl S, Maljković J B, Fedor J, Scheier P, Denifl S and Matejčík Š J Phys B: At Mol Opt Phys (2013) 46045203

Denifl S, Stano M, Stamatovic A, Scheier P and Märk T D J Chem Phys (2006) 124054320

Fenzlaff M, Gerhard R and Illenberger E J Chem Phys (1988) 88149

Fantz U, Meir S and the ASDEX Upgrade Team J Nuc Mat (2005) 337-339 1087-1091

Goldhaber D, Betz A and Ottusch J Astrophysical Journal (1987) 314356

Hinkle K, Wallace L, Richter M and Cernicharo J Proc Inter Astron Un (2008) 4161

Huber D, Beikircher M, Denifl S, Zappa F, Matejcik S, Bacher A, Grill V, Mark T and Scheier P J Chem Phys (2006) 125084304 
Huber S E, Seebacher J, Kendl A, Reiter D Contrib Plasma Phys (2011) 51 931-943

\section{$\underline{\text { http://webbook.nist.gov/chemistry/ }}$}

Krishnakumar E, Denifl S, Čadež I, Markelj S and Mason N J, Phys Rev Lett (2011) 106 243201

Mackie R, Scully S, Sands A, Browning R, Dunn K and Latimer C Int J Mass Spectr (2003) 223-224 67

Martin J M L and de Oliveira G J Chem Phys (1999) 1111843

Mauracher A, Denifl S, Aleem A, Wendt N, Zappa F, Cicman P, Probst M, Märk T D, Scheier P, Flosadottir H D, Ingolfsson O, Illenberger E Phys Chem Chem Phys (2007) 9 $5680-5685$

Melton C and Rudolph P J Chem Phys (1959) 311485

Montgomery Jr. J A, Frisch, M J, Ochterski J W, and Petersson G A J. Chem. Phys. (2000) 1126532

Nandi D, Prabhudesai V, Krishnakumar E and Chatterjee A Rev Sci Instr (2005) 76053107

Reiter D and Janev R K Contrib Plasma Phys (2010) 50 986-1013

Rienstra-Kiracofe J, Tschumper G, Schaefer H, Nandi S and Ellison G Chem Rev (2002) 102 231

Roe H, de Pater I and McKay C Icarus (2004) 169440

Rutkowsky J, Drost H and Spangenberg H Annalen der Physik (1980) 492259

Strobel D, Summers M and Zhu X Icarus (1992) 100512 
Thynne J and MacNeil K J Phys Chem (1971) 752584

Von Trepka L and Neuert H Zeitschrift fur Naturforschung A (1963) 181295 
TABLES

Table 1. An overview of previous work reporting detection of anionic fragments in DEA and DD as well as the relative abundances of the fragment anions formed in DD (Melton and Rudolph (1959), von Trepka and Neuert (1963), Thynne and MacNeil (1971)).

\begin{tabular}{|c|c|c|c|}
\hline $\begin{array}{c}\text { Product anions } \\
\text { of DD }\end{array}$ & $\begin{array}{c}\text { Melton and } \\
\text { Rudolph } \\
@ 90 \mathrm{eV}\end{array}$ & $\begin{array}{c}\text { Von Trepka and } \\
\text { Neuert } \\
@, 90 \mathrm{eV}\end{array}$ & $\begin{array}{c}\text { Thynne and } \\
\text { MacNeil } \\
@, 70 \mathrm{eV}\end{array}$ \\
\hline $\mathrm{H}^{-}$ & $\mathrm{x}$ & 4000 & 80 \\
\hline $\mathrm{C}^{-}$ & 15.2 & 1870 & 310 \\
\hline $\mathrm{CH}^{-}$ & 10.3 & 1040 & 240 \\
\hline $\mathrm{CH}_{2}^{-}$ & 4 & 470 & 110 \\
\hline $\mathrm{C}_{2}^{-}$ & 39.3 & 6650 & 1000 \\
\hline $\mathrm{C}_{2} \mathrm{H}^{-}$ & 30.1 & 4850 & 740 \\
\hline $\mathrm{C}_{2} \mathrm{H}_{2}^{-}$ & 0.9 & $\mathrm{x}$ & $\mathrm{x}$ \\
\hline $\mathrm{C}_{2} \mathrm{H}_{3}^{-}$ & 0.2 & $\mathrm{x}$ & $\mathrm{x}$ \\
\hline
\end{tabular}

\begin{tabular}{|l|l|l|}
\hline $\begin{array}{l}\text { Product anions } \\
\text { of DEA }\end{array}$ & $\begin{array}{l}\text { Von Trepka and } \\
\text { Neuert }\end{array}$ & $\begin{array}{l}\text { Thynne } \\
\text { MacNeil }\end{array}$ \\
\hline $\mathrm{H}^{-}$ & $\sqrt{ }$ & $\mathrm{x}$ \\
\hline $\mathrm{C}^{-}$ & $\mathrm{x}$ & $\mathrm{x}$ \\
\hline $\mathrm{CH}^{-}$ & $\sqrt{ }$ & $\sqrt{ }$ \\
\hline $\mathrm{CH}_{2}^{-}$ & $\sqrt{ }$ & $\sqrt{ }$ \\
\hline $\mathrm{C}_{2}^{-}$ & $\sqrt{ }$ & $\mathrm{x}$ \\
\hline $\mathrm{C}_{2} \mathrm{H}^{-}$ & $\sqrt{ }$ & $\sqrt{ }$ \\
\hline $\mathrm{C}_{2} \mathrm{H}_{2}^{-}$ & $\mathrm{x}$ & $\mathrm{x}$ \\
\hline $\mathrm{C}_{2} \mathrm{H}_{3}^{-}$ & $\sqrt{ }$ & $\mathrm{x}$ \\
\hline
\end{tabular}


Table 2.

List of adiabatic electron affinities (AEA) of anions involved in reactions

\begin{tabular}{|l||c|c|c|c|r|r|r|r|r|}
\hline AEA(eV) & $(1)$ & $(2)$ & $(3)$ & $(4)$ & \multicolumn{1}{c|}{$(5)$} & \multicolumn{1}{c|}{$(6)$} & \multicolumn{1}{c|}{$(7)$} & \multicolumn{1}{c|}{$(8)$} & \multicolumn{1}{c|}{$(9)$} \\
\hline \hline G4(MP2) & 0.75 & 0.53 & neg & 3.04 & 3.15 & 0.67 & 1.13 & 1.13 & 0.21 \\
\hline G4 & 0.68 & 0.53 & neg & 2.99 & 3.18 & 0.64 & 1.19 & 1.22 & 0.37 \\
\hline CBS & 0.75 & 0.66 & neg & 3.36 & 3.39 & 0.67 & 1.20 & 1.20 & 0.60 \\
\hline W1 & 0.68 & 0.50 & neg & 2.95 & 3.29 & 0.64 & 1.21 & 1.26 & 0.29 \\
\hline NIST & & & & $\begin{array}{r}2.9689 \\
*\end{array}$ & $3.273 *$ & $\begin{array}{r}0.210- \\
0.652 *\end{array}$ & $\begin{array}{r}0.74- \\
1.238 *\end{array}$ & $1.262 *$ & 0.75 \\
\hline
\end{tabular}

* LPES 
Table 3.

Reaction energies for reaction (1) to (9)

\begin{tabular}{|l||c|c|c|c|c|c|c|c|c|}
\hline$(\mathrm{eV})$ & $(1)$ & $(2)$ & $(3)$ & $(4)$ & $(5)$ & $(6)$ & $(7)$ & $(8)$ & $(9)$ \\
\hline \hline G4(MP2) & 3.97 & 7.56 & 7.49 & 8.85 & 13.50 & 14.63 & 18.44 & 21.96 & 22.88 \\
\hline G4 & 4.02 & 7.57 & 7.54 & 8.90 & 13.52 & 14.62 & 18.37 & 21.86 & 22.71 \\
\hline CBS & 3.99 & 7.59 & 7.46 & 9.00 & 13.60 & 14.65 & 18.46 & 21.93 & 22.52 \\
\hline W1 & 4.06 & 7.64 & 7.56 & 8.99 & 13.63 & 14.65 & 18.42 & 21.85 & 22.81 \\
\hline
\end{tabular}


Table 4.

Atomization energies (ATE) for reactions (10)-(17)

\begin{tabular}{|l||c|c|c|c|c|c|c|c|}
\hline ATE(eV) & $(10)$ & $(11)$ & $(12)$ & $(13)$ & $(14)$ & $(15)$ & $(16)$ & $(17)$ \\
\hline \hline G4(MP2) & 4.52 & 3.53 & 7.79 & 12.55 & 17.01 & 6.45 & 11.20 & 18.38 \\
\hline G4 & 4.50 & 3.52 & 7.82 & 12.56 & 17.02 & 6.38 & 11.19 & 18.37 \\
\hline CBS & 4.50 & 3.46 & 7.80 & 12.58 & 17.07 & 6.13 & 10.77 & 18.37 \\
\hline W1 & 4.48 & 3.48 & 7.81 & 12.56 & 16.94 & 6.19 & 11.16 & 18.36 \\
\hline
\end{tabular}


Table 5.

Ionization energies (IE) of ethylene and possible fragments of ethylene

\begin{tabular}{|l||c|c|c|c|c|c|c|c|c|}
\hline IE(eV) & $\mathrm{C}_{2} \mathrm{H}_{4}$ & $\mathrm{C}_{2} \mathrm{H}_{3}$ & $\mathrm{C}_{2} \mathrm{H}_{2}$ & $\mathrm{C}_{2} \mathrm{H}$ & $\mathrm{C}_{2}$ & $\mathrm{CH}_{2}$ & $\mathrm{CH}$ & $\mathrm{C}$ & $\mathrm{H}$ \\
\hline \hline G4(MP2) & 10.57 & 8.71 & 11.39 & 12.44 & 12.47 & 10.36 & 10.60 & 11.16 & 13.67 \\
\hline G4 & 10.53 & 8.70 & 11.38 & 11.68 & 12.49 & 10.38 & 10.64 & 11.22 & 13.65 \\
\hline CBS & 10.64 & 8.88 & 11.42 & 11.42 & 12.66 & 10.44 & 10.68 & 11.20 & 13.70 \\
\hline W1 & 10.52 & 8.66 & 11.35 & 11.69 & 12.45 & 10.38 & 10.63 & 11.25 & 13.61 \\
\hline NIST & 10.51 & $\begin{array}{c}8.25- \\
8.95\end{array}$ & 11.41 & $11.61-$ & $\begin{array}{c}11.41- \\
12.0\end{array}$ & $\begin{array}{c}10.35- \\
10.5\end{array}$ & 10.64 & 11.26 & 13.6 \\
\hline
\end{tabular}


Table 6. Peak positions (PP) and appearance energies (AE) for different anionic fragments formed by DEA in ethylene in comparison with previous published data. All values are presented in $\mathrm{eV}$

\begin{tabular}{|c|c|c|c|c|c|c|c|}
\hline \multicolumn{8}{|c|}{ Dissociative Electron Attachment } \\
\hline $\begin{array}{l}\mathrm{m} \\
(\mathrm{u})\end{array}$ & Anion & $\begin{array}{l}\text { Dissociation } \\
\text { channel }\end{array}$ & $\begin{array}{c}\text { Present } \\
\mathrm{PP}^{\S}\end{array}$ & $\begin{array}{l}\text { Thynne and } \\
\text { Mac Neil }^{\#} \\
\text { PP/AE }\end{array}$ & $\begin{array}{c}\text { Von Trepka } \\
\text { and Neuert } \\
\text { AE }\end{array}$ & $\begin{array}{l}\text { Cadez } \\
\text { et al. }\end{array}$ & $\begin{array}{c}\text { Present } \\
\text { Thermochemical } \\
\text { threshold }\end{array}$ \\
\hline 1 & $\mathrm{H}^{-}$ & $\begin{array}{c}\mathrm{H}^{-}+\mathrm{C}_{2} \mathrm{H}_{3} \\
\mathrm{H}^{-}+\mathrm{C}_{2} \mathrm{H}+\mathrm{H}_{2} \\
\mathrm{H}^{-}+\mathrm{CH}_{2}+\mathrm{CH}\end{array}$ & $\begin{array}{c}7.6 \\
8.8 \\
10.7\end{array}$ & & 7.6 & $\begin{array}{c}7.6 \\
9.1 \\
10.7\end{array}$ & $\begin{array}{r}4.45 \\
7.17 \\
\\
11.52\end{array}$ \\
\hline 12 & $\mathrm{C}^{-}$ & $\begin{array}{c}\mathrm{C}^{-}+\mathrm{CH}_{4} \\
\mathrm{C}^{-}+\mathrm{CH}_{2}+\mathrm{H}_{2} \\
\mathrm{C}^{-}+\mathrm{CH}_{2}+2 \mathrm{H}\end{array}$ & $\begin{array}{l}10.0 \\
15.0 \\
17.8 \\
\end{array}$ & & & & $\begin{array}{c}4.91 \\
9.56 \\
14.04 \\
\end{array}$ \\
\hline 13 & $\mathrm{CH}^{-}$ & $\begin{array}{c}\mathrm{CH}^{-}+\mathrm{CH}_{3} \\
\mathrm{CH}^{-}+\mathrm{CH}_{2}+\mathrm{H} \\
\mathrm{CH}^{-}+\mathrm{CH}+\mathrm{H}_{2} \\
\end{array}$ & $\begin{array}{c}- \\
10.0 \\
15.0\end{array}$ & $\begin{array}{l}7.9 / 7.0 \\
10.1 / 8.4\end{array}$ & $\begin{array}{l}7.3 \\
8.7\end{array}$ & & $\begin{array}{l}5.86 \\
\\
10.61 \\
10.46 \\
\end{array}$ \\
\hline 14 & $\mathrm{CH}_{2}^{-}$ & $\begin{array}{c}\mathrm{CH}_{2}^{-}+\mathrm{CH}_{2} \\
\mathrm{CH}_{2}^{-}+\mathrm{C}+\mathrm{H}_{2} \\
\mathrm{CH}_{2}^{-}+\mathrm{CH}+\mathrm{H}\end{array}$ & $\begin{array}{c}- \\
10.0\end{array}$ & $\begin{array}{c}8.8 / 7.8 \\
10.3 / 9.1\end{array}$ & 8.8 & & $\begin{array}{l}6.84 \\
10.17 \\
11.17 \\
\end{array}$ \\
\hline 24 & $\mathrm{C}_{2}^{-}$ & $\begin{array}{c}\mathrm{C}_{2}^{-}+\mathrm{H}_{2}+\mathrm{H}_{2} \\
\mathrm{C}_{2}^{-}+\mathrm{H}_{2}+2 \mathrm{H} \\
\mathrm{C}_{2}^{-}+4 \mathrm{H}\end{array}$ & 10.5 & & 10.4 & & $\begin{array}{c}4.67 \\
9.15 \\
13.63 \\
\end{array}$ \\
\hline 25 & $\mathrm{C}_{2} \mathrm{H}^{-}$ & $\begin{array}{c}\mathrm{C}_{2} \mathrm{H}^{-}+\mathrm{H}_{2}+\mathrm{H} \\
\mathrm{C}_{2} \mathrm{H}^{-}+3 \mathrm{H}\end{array}$ & $\begin{array}{c}7.5 \\
- \\
10.5\end{array}$ & $\begin{array}{c}8.5 / 6.9 \\
9.5 / 8.8 \\
10.7 / 9.8\end{array}$ & $\begin{array}{l}7.1 \\
10.0\end{array}$ & & $\begin{array}{l}4.51 \\
8.99\end{array}$ \\
\hline 26 & $\mathrm{C}_{2} \mathrm{H}_{2}^{-}$ & $\begin{array}{c}\mathrm{C}_{2} \mathrm{H}_{2}^{-}+\mathrm{H}_{2} \\
\mathrm{C}_{2} \mathrm{H}_{2}^{-}+\mathrm{H}+\mathrm{H} \\
\end{array}$ & 7.4 & & & & $\begin{array}{l}3.16 \\
7.64 \\
\end{array}$ \\
\hline 27 & $\mathrm{C}_{2} \mathrm{H}_{3}^{-}$ & $\mathrm{C}_{2} \mathrm{H}_{3}^{-}+\mathrm{H}$ & $\begin{array}{c}7.5 \\
10.5 \\
\end{array}$ & & & & 4.06 \\
\hline
\end{tabular}

${ }^{\S}$ Estimated uncertainty of values \pm 0.2

${ }^{\text {\# }}$ Estimated uncertainty of values \pm 0.3

${ }^{*}$ Estimated uncertainty of values $\pm 0.3-0.4$ 
Table 7. Thermochemical thresholds for the DD processes in ethylene. The appearance energy for the production of positive ion, $\mathrm{AE}_{\mathrm{B}}$, and the electron affinities $\mathrm{AE}_{\mathrm{A}}$ were taken from the present thermochemical data except the EA for $\mathrm{H}$ which was taken from RienstraKiracofe et al. 2002. The last column of the table includes the present experimental value of energy threshold of DD process. All values are presented in $\mathrm{eV}$.

\begin{tabular}{|c|c|c|c|c|c|}
\hline \multicolumn{5}{|c|}{ Dipolar Dissociation } \\
\hline Anion & $\begin{array}{c}\text { Dissociation } \\
\text { channel } \\
\mathrm{A}^{-}+\mathrm{B}^{+}(+\mathrm{C})\end{array}$ & $\mathrm{AE}_{\mathrm{B}}$ & $\mathrm{EA}_{\mathrm{A}}$ & $\begin{array}{c}\text { EthDD } \\
\text { thermochemical }\end{array}$ & $\begin{array}{c}\text { EthDD } \\
\text { experimental }\end{array}$ \\
\hline $\mathrm{H}^{-}$ & $\mathrm{H}^{-}+\mathrm{C}_{2} \mathrm{H}_{3}^{+}$ & 13.4 & 0.75 & 12.65 & $13.5 \pm 0.5$ \\
& $\mathrm{H}^{-}+\mathrm{C}_{2} \mathrm{H}_{2}^{+}+\mathrm{H}$ & 11.35 & 0.75 & 18.53 & \\
& $\mathrm{H}^{-}+\mathrm{C}_{2} \mathrm{H}^{+}+\mathrm{H}_{2}$ & 19.15 & 0.75 & 18.4 & \\
\hline $\mathrm{CH}_{2}^{-}$ & $\mathrm{CH}_{2}^{-}+\mathrm{CH}_{2}^{+}$ & 17.86 & 0.64 & 17.22 & $18.2 \pm 0.5$ \\
& $\mathrm{CH}_{2}^{-}+\mathrm{C}^{+}+\mathrm{H}_{2}$ & 22.06 & 0.64 & 21.42 & \\
\hline $\mathrm{C}_{2} \mathrm{H}_{3}^{-}$ & $\mathrm{C}_{2} \mathrm{H}_{3}^{-}+\mathrm{H}^{+}$ & 18.35 & 0.68 & 17.67 & $21.5 \pm 0.5$ \\
\hline
\end{tabular}




\section{FIGURES}

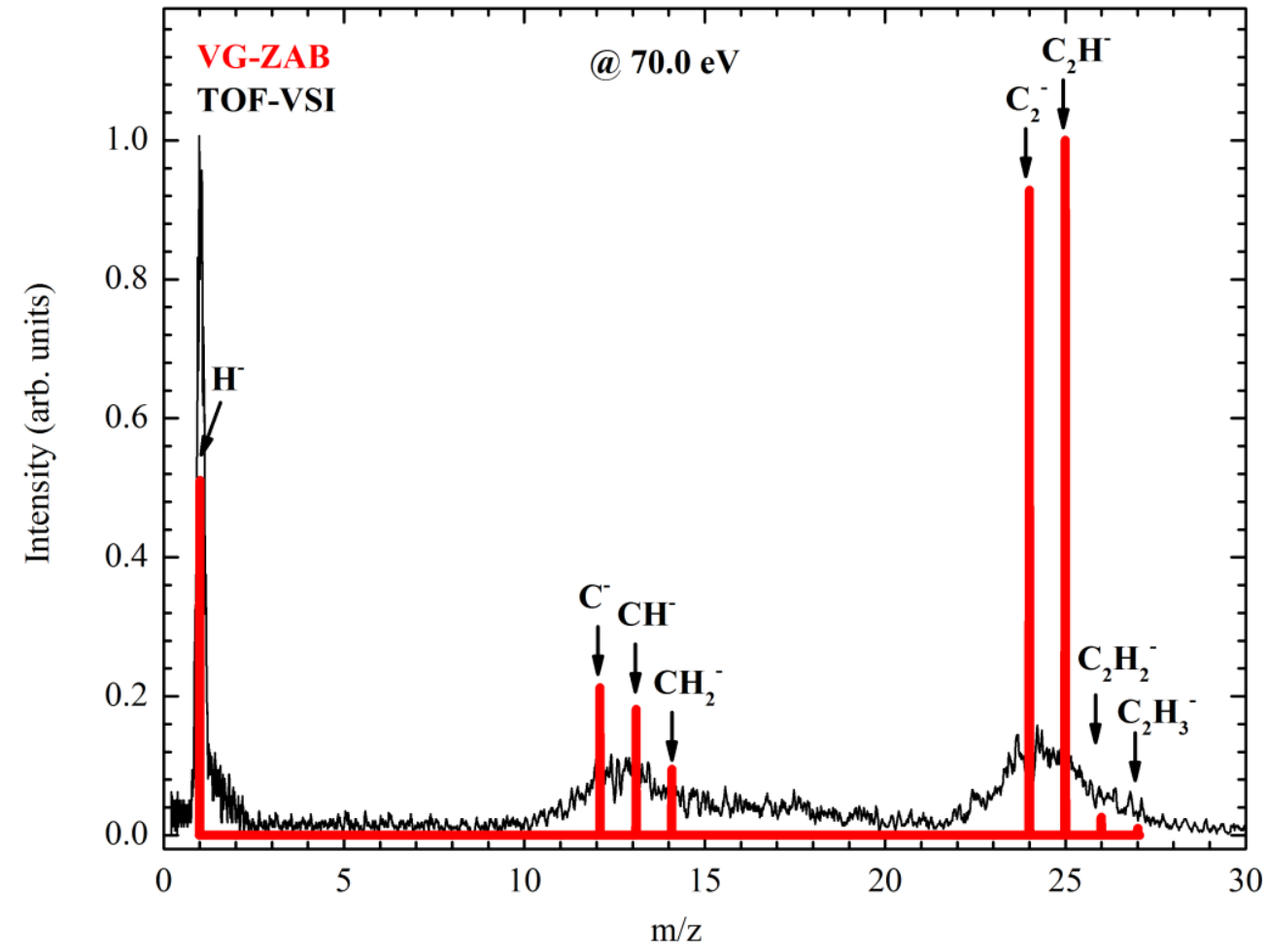

Figure 1. Anionic mass spectra of ethylene recorded at an incident electron energy of $70.0 \mathrm{eV}$ using two experimental apparatuses: VG-ZAB (thick solid line) and TOF-VSI (thin solid line). 


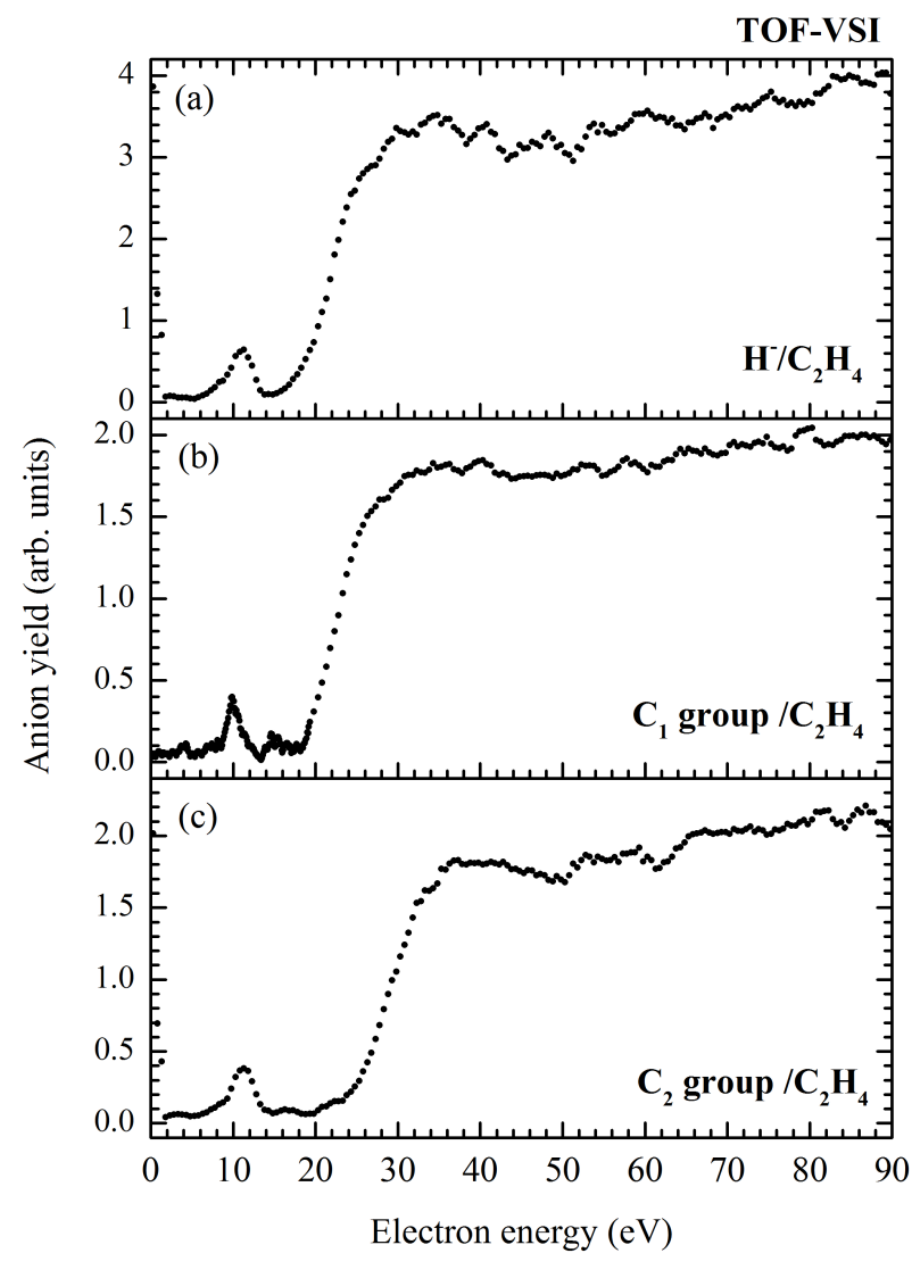

Figure 2. Anion yields of $\mathrm{H}^{-}$(a), $\mathrm{C}_{1}$ anion group (b) and $\mathrm{C}_{2}$ anion group (c) from $\mathrm{C}_{2} \mathrm{H}_{4}$ as a function of incident electron energy range of $0-90 \mathrm{eV}$ recorded using the TOF-VSI spectrometer (circles). 


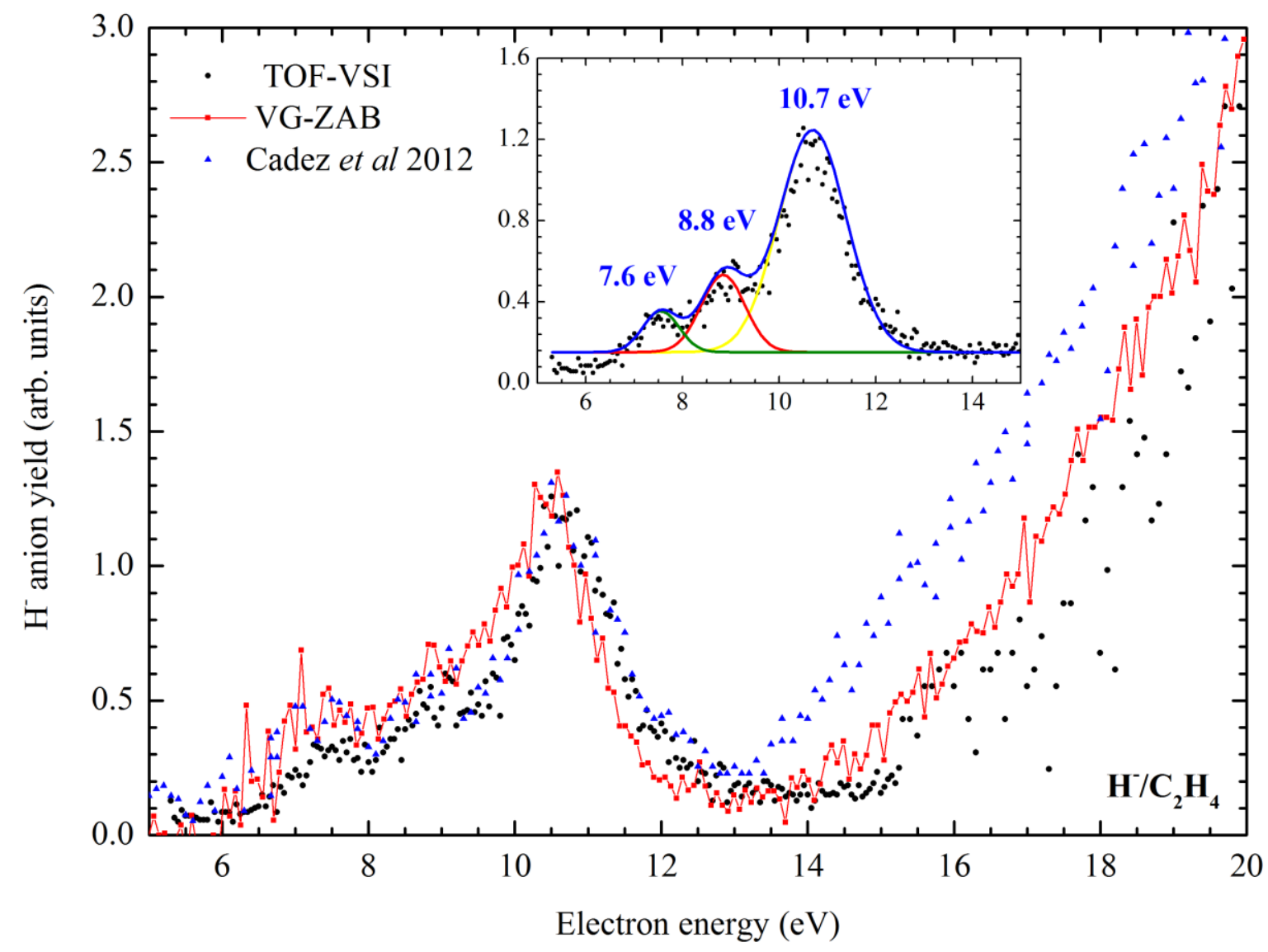

Figure 3. Anion yield of $\mathrm{H}^{-} / \mathrm{C}_{2} \mathrm{H}_{4}$ as a function of incident electron energy range of $5-20 \mathrm{eV}$ recorded using the TOF-VSI apparatus (circles), VG-ZAB yield (squares with line) and recent work by Cadez et al. 2012 (triangles). The inset shows the $\mathrm{H}^{-}$anion yield at low electron energies (circles), while the solid line presents the resonance peak position determined by Gaussian fitting. 


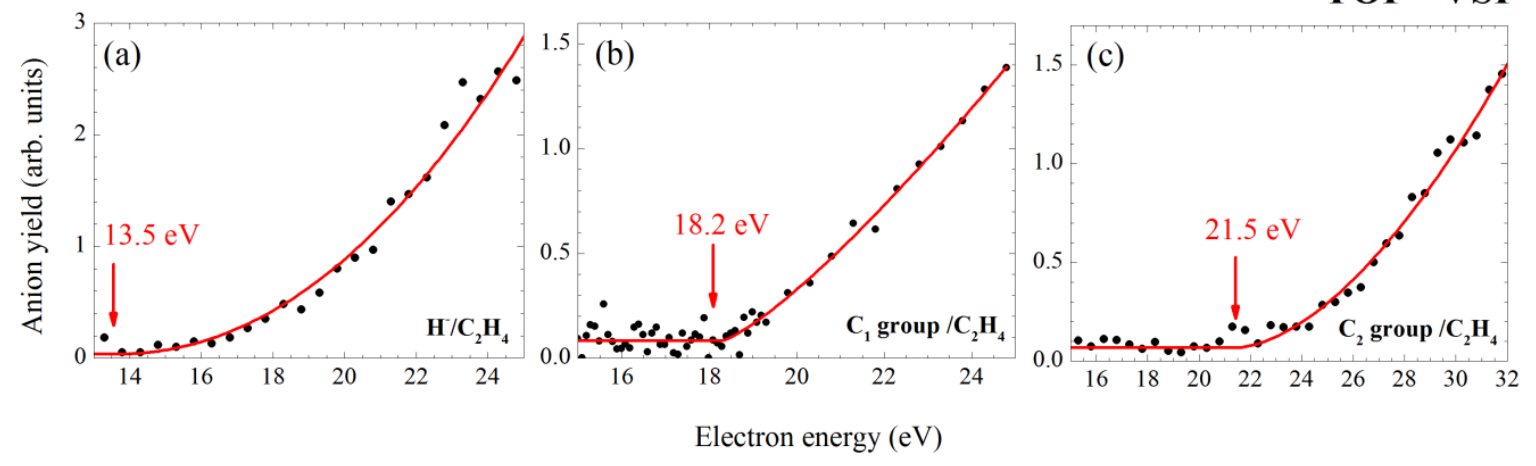

Figure 4. Anion yields for ethylene as a function of electron energy (scatters) collected using the TOF-VSI apparatus. The electron energy ranges shows the fitted energy thresholds of the DD processes for three groups of anions (arrows). 


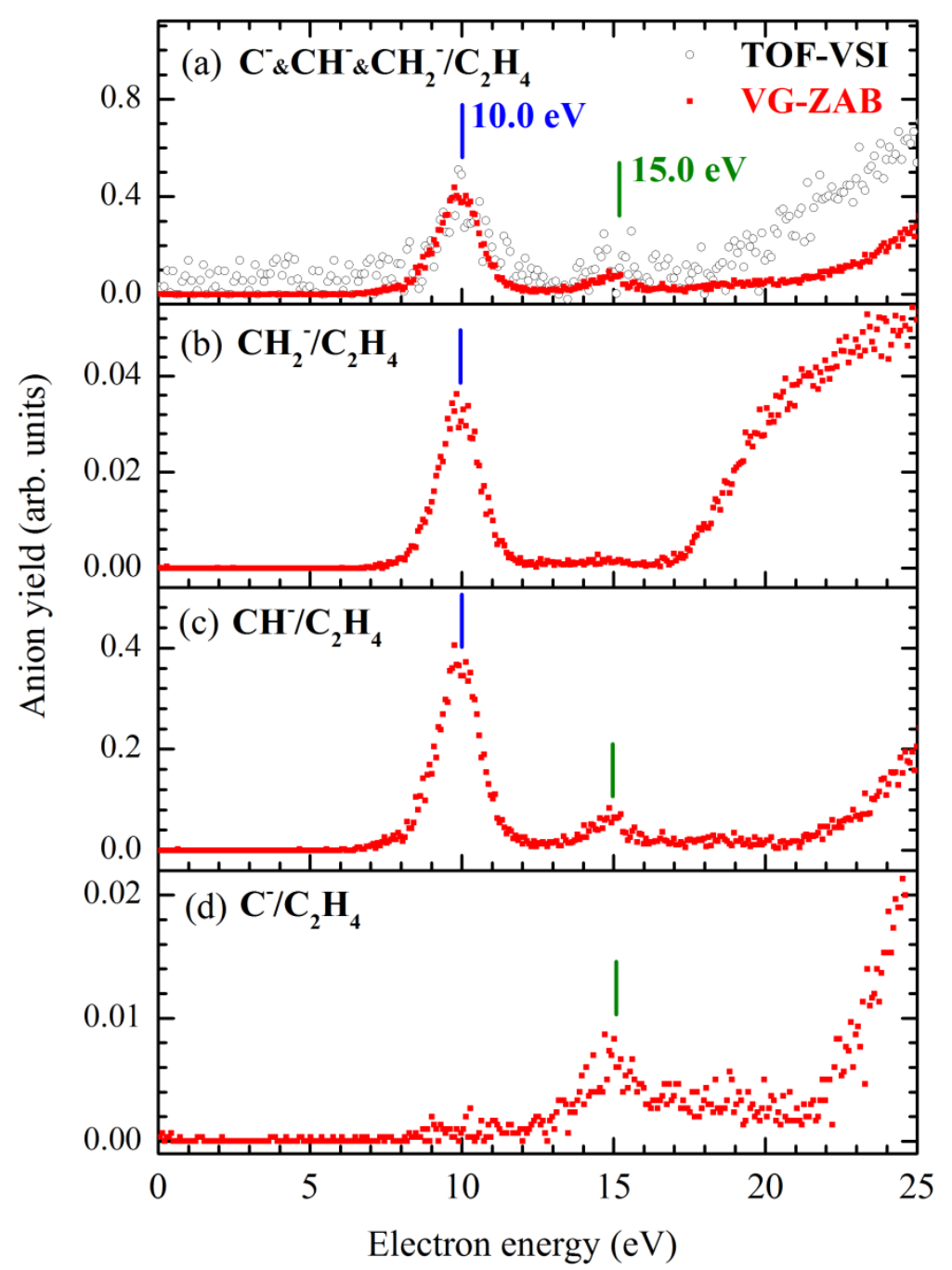

Figure 5. Panel (a) compares the sum of $\mathrm{C}^{-}, \mathrm{CH}^{-}$and $\mathrm{CH}_{2}^{-}$yields recorded using the VGZAB experiment (solid squares) with the $\mathrm{C}^{-} / \mathrm{CH}^{-} / \mathrm{CH}_{2}^{-}$from $\mathrm{C}_{2} \mathrm{H}_{4}$ yield recorded using the TOF-VSI experiment (open circles). Panels (b) - (d) show the anion yield of $\mathrm{C}^{-}, \mathrm{CH}^{-}$and $\mathrm{CH}_{2}^{-} / \mathrm{C}_{2} \mathrm{H}_{4}$ as a function of incident electron energy range of $0-25 \mathrm{eV}$ recorded using the VG-ZAB apparatus. The dashes indicate the resonance peak position at about 10.0 and 15.0 $\mathrm{eV}$, respectively. 


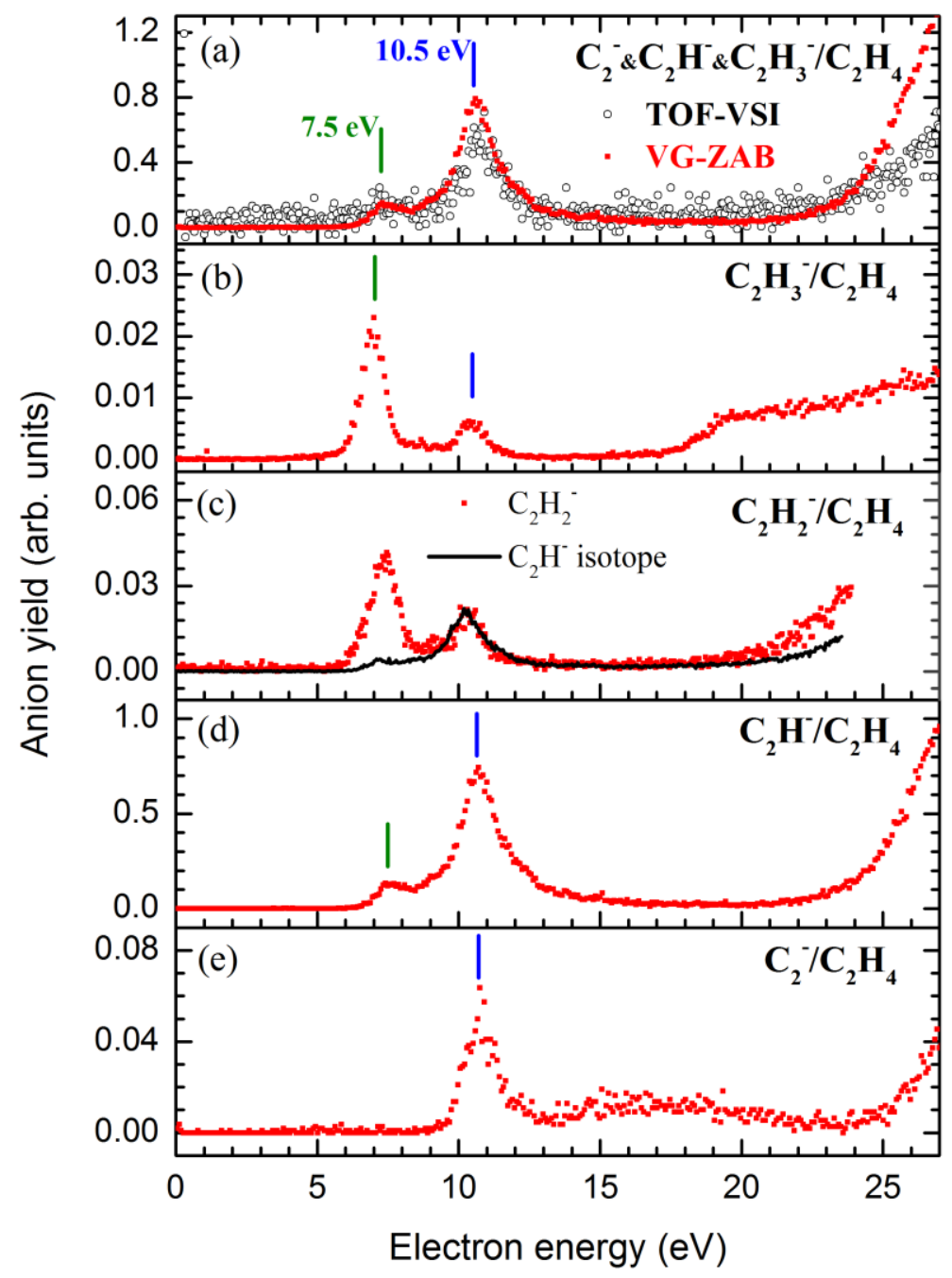

Figure 6. Panel (a) shows the comparison of the sum of $\mathrm{C}_{2}^{-}, \mathrm{C}_{2} \mathrm{H}^{-}, \mathrm{C}_{2} \mathrm{H}_{2}^{-}$and $\mathrm{C}_{2} \mathrm{H}_{3}{ }^{-}$yields recorded using the VG-ZAB experiment (solid squares) with the $\mathrm{C}^{-} / \mathrm{CH}^{-} / \mathrm{CH}_{2}{ }^{-}$from $\mathrm{C}_{2} \mathrm{H}_{4}$ yield recorded using the TOF-VSI experiment (open circles). Panels (b) - (e) show the anion yield of $\mathrm{C}^{-}, \mathrm{CH}^{-}$and $\mathrm{CH}_{2}^{-} / \mathrm{C}_{2} \mathrm{H}_{4}$ as a function of incident electron energy range of $0-25 \mathrm{eV}$ recorded using the VG-ZAB apparatus. The dashes indicate the resonance peak position at about 7.5 and $10.5 \mathrm{eV}$, respectively. 